\title{
Molecular detection of methicillin resistant Staphylococcus aureus harbouring $\beta$ - lactamase resistance genes isolated from different sources of infections
}

\begin{abstract}
Amir Hani Raziq* Ahmed Mohammed Sulaiman* Narmin Saeed Merza* Zainab Hasan Abdullah*
Abstract

Background and objective: The detection and investigation of methicillin resistance staphylococci specifically $S$. aureus in clinical microbiology setting is very helpful both for informing the appropriate treatment of individual patients and also for the surveillance of these organisms. This study aimed at the rapid molecular detection of methicillin resistant staphylococci harbouring $\beta$-lactamase gene and determination of the efficiency of $\mathrm{m}$-PCR through comparison with uniplex PCR.

Methods: Standard microbiological techniques were applied for the determination of the presence of methicillin resistant $S$. aureus in samples recovered from different body sites of patients who attended Al-Kadhumyhia Teaching and Baghdad Teaching Hospitals. The resulting methicillin resistant $S$. aureus (MRSA) isolates were subjected to uni and multiplex PCR amplifications for detecting the existence of mec A gene and $\beta$-lactamase (TEM) resistance gene.

Results: Half of the cases involved were found to be caused by MRSA. All the tested isolates showed positive amplification bands for the presence of mec A gene and only $48.8 \%$ of these harbored TEM gene. The obtained results revealed high sensitivity of universal bacterial and TEM primers expressed as $97.6 \%$ and $100 \%$ respectively, while the sensitivity of mec A primer was limited to $60 \%$.

Conclusion: The phenotypic identification of MRSA revealed a higher incidence rate and that different molecular techniques can yield conflicting results and it can also be concluded that resistant due to beta- lactamase production can be a crucial factor added to the previously settled methicillin resistant due to mec A gene.
\end{abstract}

Keywords: Methicillin resistant Staphylococcus aureus; mec A; TEM; multiplex- PCR; Uniplex-PCR

\section{Introduction}

The emergence of Methicillin resistant coagulase positive, Staphylococcus aureus and most coagulase negative staphylococci play an important role for the increased incidence of nosocomial infections worldwide. ${ }^{1}$ Methicillin resistance mediated by the mec A gene which encodes for a penicillin-binding protein named PBP2a which is responsible for resistance to virtually all $\beta$-lactam group and their derivatives due to its decreased binding affinity. ${ }^{2}$ The detection and identification of methicillin resistance staphylococci specifically $S$. aureus in the clinical microbiology setting is very helpful both for informing the appropriate treatment of individual patients and also for the surveillance of these organisms. ${ }^{3}$ Indeed, there are many ways for detecting Methicillin resistance (MR) such as determining MICs (e.g. broth dilution), screening procedures with hardened culture medium and methods that depend on detection of mec A gene or its encoded protein (PBP2a). ${ }^{4}$ However, the detection of MR via classical methods may have several drawbacks because of heterogeneity in expression by Staphylococcus population, ${ }^{5}$ and they can be labor intensive and time consuming. Detection of mec A gene is reliable

* Scientific Research Center, College of Sciences, University of Duhok, Duhok, Iraq. 
approach for rapid investigation of MR isolates; Nowadays control policies to minimize the emergence and rapid distribution of these microorganism dependon accurate and sensitive techniques for identifying of MR carriers. ${ }^{6}$ Therefore, this study aimed to assess the application of m-PCR method for rapid identification of methicillin resistant staphylococci harbouring $\beta$-lactamase gene and determining the efficiency of m-PCR through comparison with uniplex PCR using RW01, DG74, TEM-1, TEM-2, MRS-1, and MRS- 2 primers.

\section{Methods}

\section{Samples collection}

One hundred specimens were obtained from several body parts and lesions of in and out patients from both sexes who attended Al-Kadhumyhia Teaching Hospital and Medical Laboratories in Baghdad Teaching Hospital during the period from March until September 2012. All specimens were sub-cultured on culture media for primary bacterial identification. Phenotypic identification and characterization to these isolates have performed according to the literatures. ${ }^{7}$

Identification of Methicillin resistant isolates by disk diffusion test

The studied isolates were challenged with oxacillin $(1 \mu \mathrm{g})$ disks, using Mueller-Hinton agar plates streaked separately with a particular isolates. Incubation of the plates at $37{ }^{\circ} \mathrm{C}$ for 24 hours proceeded and the resulting zones of inhibition were measured. The CLSI 2005 criteria $(\mathrm{CLSI}, 2005)^{8}$ were used for interpretation (Table 1).

\section{Extraction of Genomic DNA}

Genomic DNA was extracted as proposed by the literatures, ${ }^{9}$ the concentration and purity of the extracted DNA were determined using Nano-drop system.

\section{Agarose gel electrophoresis}

Agrose gel (1.0 \%) was prepared according to previous work and electrophoresis was adopted to confirm the presence DNA. $^{10}$

PCR Assays

Uniplex PCR assay was performed for each of the three primers individually (Table 2). Lyophilized master mix was

Table 1: 2005 CLSI interpretation guideline for Methicillin resistant S. aureus recovered from different sources infections.

\begin{tabular}{llll}
\hline Antibiotic & \multicolumn{3}{l}{ Inhibition zone (mm) } \\
\hline Oxacillin & $\leq 10(\mathrm{R})$ & $11-12(\mathrm{I})$ & $\geq 13(\mathrm{~S})$ \\
\hline
\end{tabular}

R: resistant, I: Intermediate, S: Sensitive

Table 2: Primers used to amplify target sequences.

\begin{tabular}{lcrc}
\hline Gene & Primers & Sequences 5'-3' & $\begin{array}{c}\text { Amplicon } \\
\text { size (bp) }\end{array}$ \\
\hline Bacterial universal & RW01 (F) & 5' AACTGG AGG AAG GTG GGG AT3' & 370 \\
& DG74 (R) & 5' AGGAGG TGA TCC ACC CGC A3' & \\
b-lactamase resistant & TEM-1 (F) & 5' CGG CAT TTT GCC TTC CTG TTTTTG C3' & 702 \\
gene & TEM-2 (R) & 5' GGC CCC AGT GCT GCA ATGATA CCG3' & \\
mec A gene & MRS-1(F) & 5' GAA ATG ACT GAA CGT CCGAT3' & 150 \\
& MRS-2(R) & 5' GCG ATC AAT GTT ACC GTAGT3' & \\
\hline
\end{tabular}


reconstituted by adding $16 \mu \mathrm{l}$ D.W., $2 \mu \mathrm{l}$ Primers (Forward and reverse), and $2 \mu \mathrm{l}$ DNA template $(50 \mathrm{ng} / \mathrm{ml})$. Moreover, Multiplex PCR reaction was also done for the same three primers in $20 \mu l$ reaction volume. Each reaction tube contained lyophilized PCR master mix; the mix was reconstituted by adding $12 \mu \mathrm{l}$ PCR-grade water along with three primers $(10 \mathrm{pmol})$, and $2 \mu$ DNA template (50 ng). The same conditions were applied for both uniplex and multiplex PCR. Thirty cycles of amplification were performed in Biosystem thermal cycler. Five minutes step was carried out at $95{ }^{\circ} \mathrm{C}$ for denaturing DNA, 30 seconds for annealing at $55{ }^{\circ} \mathrm{C}$, and 30 second extension step at $72{ }^{\circ} \mathrm{C}$, finally, extension step at $72{ }^{\circ} \mathrm{C}$ for 7 minutes. ${ }^{11}$ Amplification products were detected by running on $2 \%$ agarose gel electrophoresis and visualized with UV illumination after being stained with ethidium bromide for 15 minutes. Standard DNA 100 bp molecular marker was included in each run.

\section{Results}

Fifty isolates of MRSA were recovered from a total of 100 clinical samples of staphylococci accounting for $50 \%$ of bacterial isolates collected from different body samples (Table 3 ). The preliminary phenotypic identification was further augmented by subjecting bacterial isolates to Oxacillin antibiotic sensitivity test and it was clear that all the fifty isolates were methicillin resistant by showing inhibition zones of less than $10 \mathrm{~mm}$ thus confirming primary result. The results of the present study showed that DNA has been extracted from 41 isolates of MRSA, the average concentration of DNA was $610 \mathrm{ng} / \mu \mathrm{l}$ and the purity was 1.9 . The concentration of genomic DNA of those isolates were justified to $50 \mathrm{ng} / \mu \mathrm{l}$ and compared with undigested $\wedge$ DNA (Figure 1).

Table 3: Methicillin resistant Staphylococcus aureus isolated from different pathological lesions.

\begin{tabular}{lc}
\hline Cases & No. of isolates (\%) \\
\hline Wounds swabs & $15(30)$ \\
Ear swabs & $5(10)$ \\
Sputum & $10(20)$ \\
Urine samples & $6(12)$ \\
Urethral discharge & $4(8)$ \\
Vaginal swabs & $3(6)$ \\
Blood samples & $7(14)$ \\
Total & $50(100)$ \\
\hline
\end{tabular}

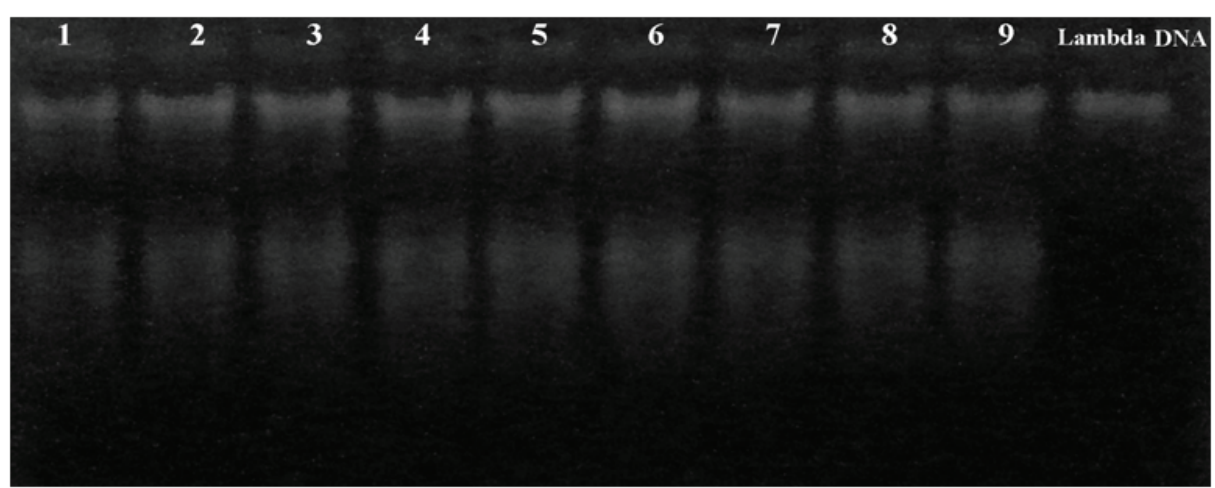

Figure 1: Genomic DNA of Stapylococcus aureus strains, the last Line represents lambda DNA with concentration 50ng/ul running on $1 \%$ agarose gel, The last line represents uncut $\lambda$ DNA marker (25ng) as standard molecular weight marker. 
In the present study, all isolates and mecA gene correspondent to $370 \mathrm{bp}$ successfully produced uni-plex PCR and $150 \mathrm{bp}$, respectively (Figures 2 and 3 ). amplification products of universal primer

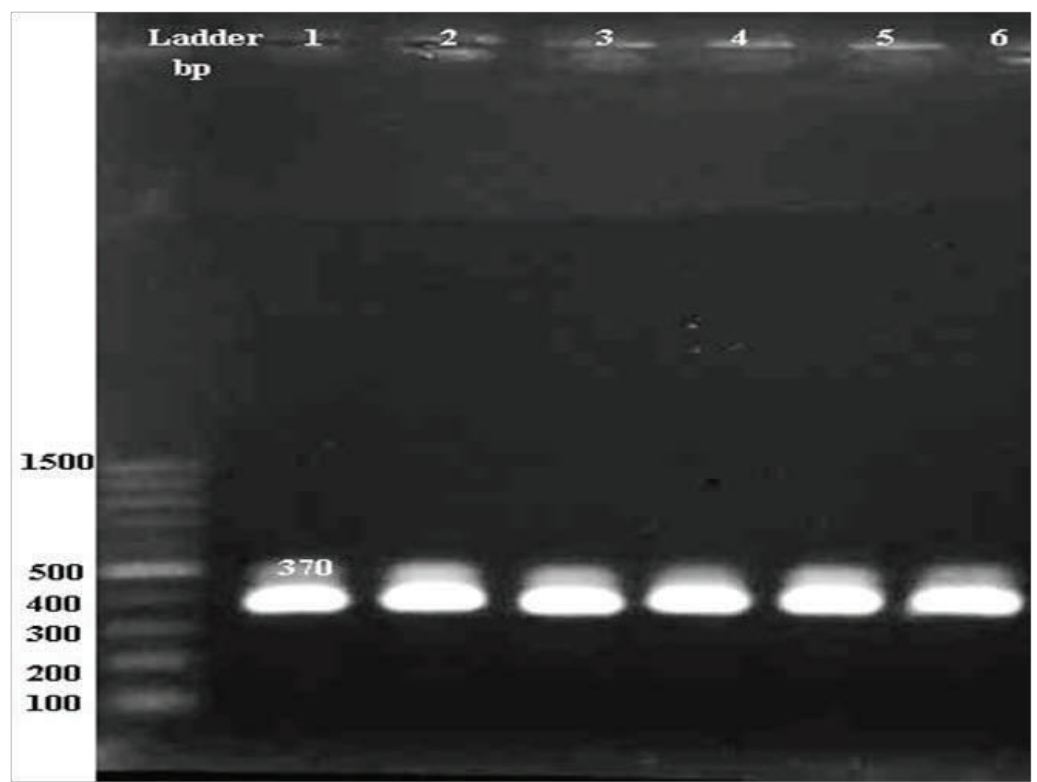

Figure 2: Amplification of bacterial universal gene evident by 370 bp bands on $1.5 \%$ agarose gel and run with $5 \mathrm{~V} / \mathrm{Cm}$, for 1 hour. The first Lane contained DNA molecular weight marker (100bp).

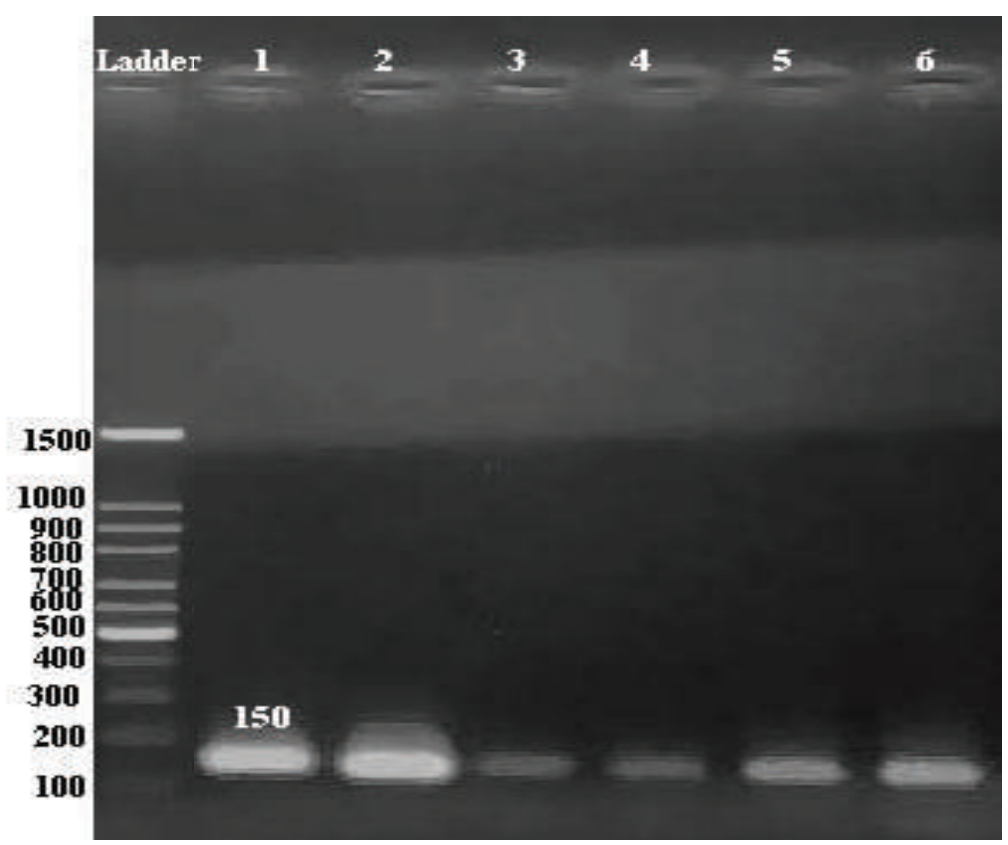

Figure 3: Amplification bands of mec A gene (150 bp) run on $1.5 \%$ agarose gel and run with $5 \mathrm{~V} / \mathrm{Cm}$, for 1 hour. The first Lane contained DNA molecular weight marker (100bp). 
Moreover, twenty samples only out of the $41(48.7 \%)$ showed an amplicon of 702 bp which stood for b-lactamase gene (Figure 4). For the multi-plex PCR assay, it was clear that all the 41 MRSA isolates showed amplification product correspondent to universal bacterial gene; while mec A gene was successfully amplified in 25 isolates $(60.9 \%)$, on the other hand, PCR amplification for b-lactamase gene revealed the same result as for the uniplex PCR (Figure 5).

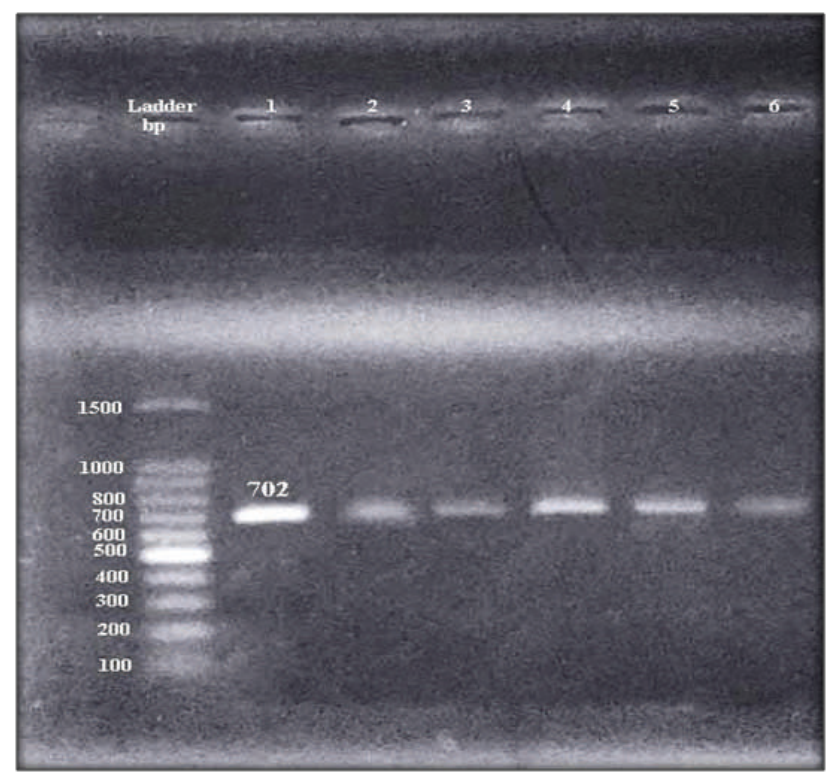

Figure 4: Amplifications bands of 702 run on $1.5 \%$ agarose gel correspondent to b-lactamase gene, agarose $1.5 \%$ was used for electrophoresis was and run on $5 \mathrm{~V} / \mathrm{Cm}$, for 1 hour. The first lane contained DNA molecular weight marker (100bp).

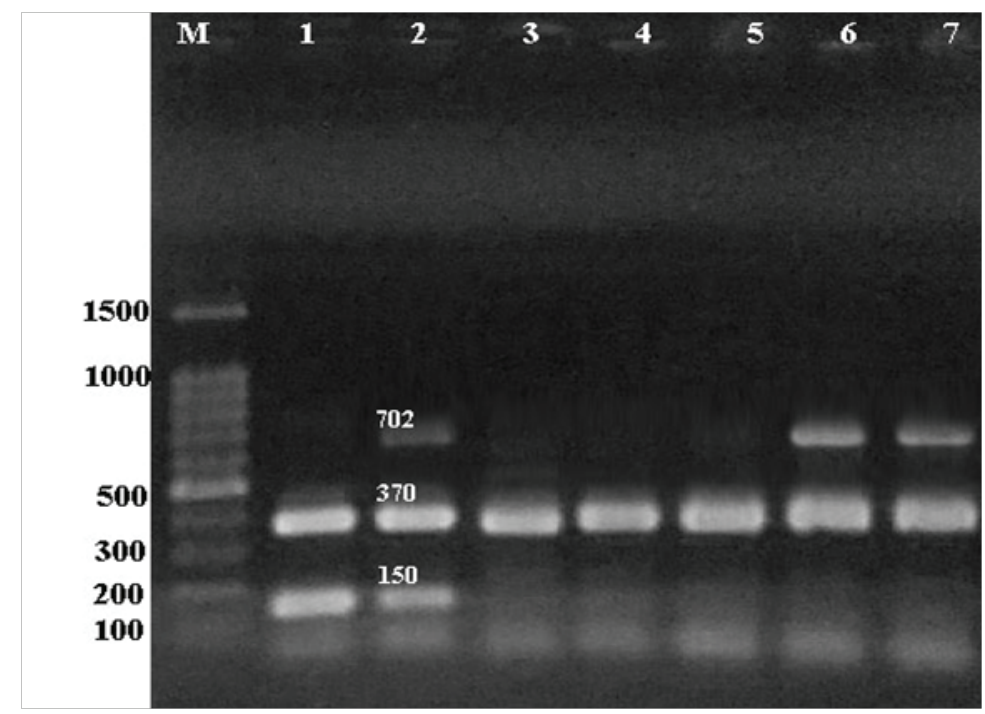

Figure 5: Multiplex PCR amplifications for the three genes. Lane 2 shows the three amplification bands of $150 \mathrm{bp}, 370 \mathrm{bp}$, and $702 \mathrm{bp}$ correspondents to mec A genes, bacterial universal gene, and b-lactamase gene, respectively. Electrophoresis was done on $1.5 \%$ agarose and run on $3 \mathrm{~V} / \mathrm{Cm}$, for 1 hour. The first lane contained DNA molecular weight marker (100bp). 
Collectively, the results of the present study revealed that $100 \%$ of isolates showed positive amplification reactions for universal bacterial gene with both uni-plex and multi-plex PCR assays; while mec A gene was detected in $100 \%$ of samples with uni-plex PCR and in only $60.9 \%$ of isolates when multi-plex PCR was applied. Moreover, $48.7 \%$ of samples revealed that they harbored b-lactamase producing gene when both types of PCR were used (Table 4).

\section{Discussion}

The inappropriate usage of antibiotics for infection treatment has signalled a rapid development and dissemination of antibiotic resistance phenotype in microorganisms, especially in human pathogens. Moreover, a trend to an elevated count and virulence of Grampositive bacteria has been noticed in the last decades. These microorganisms share the tendency to gather several resistances under conditions of antibiotic use and selection. ${ }^{11}$ Methicillin-resistant Staphylococcus aureus (MRSA), that have gained multi-resistance to several groups of antibacterials, have become an alarming nosocomial pathogen and the appearance of the primary MRSA with decreased susceptibility to vancomycin elicited the suspicions of an entirely resistant $S$. aureus. In fact, the accelerated emergence of antibiotic resistance can be attributed to mutational traits and/or gene transfer and gaining of resistance genes, providing strains with opportunities to combat antibiotic therapy. ${ }^{12}$ In previous study, low-level methicillin resistance of staphylococcal isolates was linked with the presence of the mec-A gene and overproduction of $\beta$-lactamase. ${ }^{13}$
Interestingly, methicillin-resistant strains are now classified as being as $\beta$-lactamase hyper-producers. ${ }^{14} \quad \beta$-lactamase confers resistance to penicillins, cephalosporins by their ability to bind and destroy these antibiotics before they reach their target location. ${ }^{15}$ The results of the present study came in agreement with that of other researchers who compared multiplex PCR for the identification of antibiotic resistance genes with conventional methods for the detection of susceptibility to antibiotics and they found that twenty four isolates primarily described as methicillin resistant depending on disk diffusion showed conflicting results when examined with multiplex PCR and mec A was positive in 16 out of $24(66.7 \%)$ isolates. The discrepant findings between phenotypic and genotypic outcomes can be attributed to technical errors. Furthermore, the findings of the current study were inconsistent with other researchers who stated that $83.3 \%$ of the $S$. aureus isolates were producing $\beta$-lactamase and it was postulated that despite the expression of the mec A gene which can be considered as an essential mechanism of resistance, other mechanisms alone or in combination have been found in Staphylococci. ${ }^{16}$ Controversial data are still argued about the reliability of the ordinary susceptibility testing techniques, including disk diffusion and agar dilution tests, in detecting methicillin resistant staphylococci. ${ }^{17}$ When uni-plex PCR was considered, the results of the present study came in line with another which revealed that all phenotypically identified MRSA isolates showed positive PCR yield for mec A gene but contradictory findings appeared as far as Multiplex PCR was considered. Determination of resistance to methicillin in

Table 4: Results of PCR experiments with three primers.

\begin{tabular}{lcccc}
\hline PCR type & No. of samples & Universal primers & Mec- $\boldsymbol{A}$ & TEM-1 \\
\hline Uni-plex PCR & 41 & $41(100 \%)$ & $41(100 \%)$ & $20(48.7 \%)$ \\
Muti-plex PCR & 41 & $41(100 \%)$ & $25(60.9 \%)$ & $20(48.7 \%)$ \\
\hline
\end{tabular}


staphylococci by conventional methods is obviously affected by variations in inoculum size, time of incubation, $\mathrm{pH}$ of the medium, and concentration of salts. ${ }^{18}$ From a clinical point of view, it is essential to distinguish isolates which are mec A positive, which is the classic type of methicillin resistance, from the infrequently encountered isolates that have one of the other types of more subtle or borderline resistance due to hyperproduction of beta-lactamases. ${ }^{2}$ It is worthy to state that the use of PCR technique in clinical settings has many potential limitations due to the sensitivity of PCR to inhibitors, contaminants and experimental situations. It has been documented that the sensitivity and specificity of a PCR assay are both affected by intended genes, sequences of primers, PCR techniques, DNA extraction method, and product detection techniques. ${ }^{19}$ Nevertheless, multiplex PCR (mPCR) is becoming an accurate and reliable screening assay in both clinical and research conditions. ${ }^{20}$ However, the optimization of multiplex PCR may have many drawbacks, including decreased specificity and sensitivity, and bias to amplifying distinct specific targets. ${ }^{21}$

\section{Conclusion}

The phenotypic identification of MRSA revealed a higher incidence rate and that different molecular techniques can yield conflicting results and it can also be concluded that resistant due to betalactamase production can be a crucial factor added to the previously settled methicillin resistant due to mec $\mathrm{A}$ gene.

\section{Conflicts of interest}

The authors report no conflicts of interest.

\section{References}

1. Khadri $\mathrm{H}$, Alzohairy M. Prevalence and antibiotic susceptibility pattern of methicillin-resistant and coagulase-negative staphylococci in a tertiary care hospital in India. Int J Med Med Sci 2010; 2(4):116-20.

2. Chambers HF. Methicillin resistance in staphylococci: Molecular and biochemical basis and clinical implications. Clin Microbiol Rev
1997; 10:781-91.

3. Paterson GK, Harrison EM, Holmes MA. The emergence of mec $C$ methicillin resistant Staphylococcus aureus. Trends Microbiol 2014; 22(1):42-7.

4. Samah SE, Mohamad S, Mohamad S. Accuracy of Phenotypic Methods in Detection of Methicillin Resistant Staphylococci Species Compared to PCR Assay for mecA Gene. Egypt J Med Micro 2009; 18(1):33-40.

5. Matthews PR, Stewart PR. Resistance heterogeneity in methicillin-resistant Staphylococcus aureus. FEMS Microbiol Lett 1984; 22:161-6.

6. Ann H, Pierre L, Francois JP, Marthe B, Martin G, Nathalie B, et al. Identification of Methicillin-Resistant Staphylococcus aureus Carriage in Less than 1 Hour during a Hospital Surveillance Program. Clin Infect Dis 2005; 40:976-81.

7. Baron EJ, Peterson LR, Finecold SM. Diagnostic microbiology. $5^{\text {th }}$ ed. Toronto Canada: The C.V. Mesby Company; 1994. p. 429-43.

8. Clinical and Laboratory Standards Institute. Performance standards for antimicrobial susceptibility testing. Fifteenth informational supplement, document M100-S15. CLSI, Wayne, Pa, USA; 2005.

9. Al-Mizory S. Study of the Bacterium Pseudomonas aeruginosa Isolated from Different Sources at Dohuk City. M. Sc. Thesis. College of Education, Dohuk University. Iraq; 2007.

10. Sambrook J, Fritsch EF, Maniatis T. Molecular cloning: A laboratory manual. $2^{\text {nd }}$ ed. New York: Cold spring harbor laboratory press; 1989.

11. Sadeghian S, Neyestani TR, Burnie JP. Detection of Bacterial, Methicillin resistance, and b. Lactamase enzyme gene found in wound swabs by Multiplex Polymerase Chain Reaction. Acta Medica Iranica 2004; 42(1):19-25.

12. Berger-Bachi, B. Resistance mechanisms of Gram positive bacteria. Int J Med Microbiol 2002; 292(1):27-35.

13. Petinaki E, Arvaniti A, Bartzavali C, Dimitracopoulos G, Spiliopoulou I. Presence of mec genes and overproduction of $\beta$-lactamase the expression of low-level methicillin resistance among staphylococci. Chemotherapy 2002; 48(4):174-81.

14. Corrente M, Greco G, Madio A, Ventrigila G. Methicillin resistance in staphylococci isolated from subclinical mastitis in sheep. New Microbiol 2003; 26(1):39-45.

15. Perez-Perez FJ, Hanson ND. Detection of plasmid-mediated AmpC beta-lactamase genes in clinical isolates by using multiplex PCR. J Clin Microbiol 2002; 40(6):2153-62.

16. Ribas RM, Gontijo-Filho PP, Darini LC. Conventional versus molecular tests (multiplex PCR and PCR mec A gene) for detection of methicillin resistant Staphylococcus aureus. 
Braz J Microbiol 2003; 34(Suppl.1):35-7.

17. Martineau F, Picard FJ, Lansac N, Nenard C, Roy $\mathrm{PH}$, Ovellehe $\mathrm{M}$, et al. Correlation between the resistance genotype determined by multiplex PCR assays and the antibiotic susceptibility patterns of Staphylococcus aureus and S. epidermidis. Antimicrobial Agents Chemother 2000; 44:231-8.

18. Mohanasoundaram KM, Lalitha MK. Comparison of phenotypic versus genotypic methods in the detection of methicillin resistance in Staphylococcus aureus. Indian J Med Res 2008; 127:78-84.

19. Yoshimasa Y. PCR in Diagnosis of Infection: Detection of Bacteria in Cerebrospinal Fluids. Clin Diagn lab Immunol 2002; 9(3):508-14.

20. Markoulatos $P$, Siafakas N, Moncany $M$. Multiplex Polymerase Chain Reaction: A Practical Approach. J Clin Lab Anal 2002; 16:47-51.

21. Elnifro EM, Ashshi AM, Cooper RJ, Klapper PE. Multiplex PCR. Optimization and Application in Diagnostic Virology. Clin Microbiol Rev 2000; 13(4):559-70. 